\title{
ANÁLISE DO DESEMPENHO DAS MELHORES PRÁTICAS DE MANEJO PARA CONSTITUIÇÃO DE CORREDORES VERDES EM FORTALEZA-CE.
}

\author{
BEST MANAGEMENT PRACTICES PERFORMANCE'S ANALYSIS \\ FOR THE CONSTITUTION OF GREENWAYS IN FORTALEZA - CE
}

\author{
Raquel Moraes Vitor Cortez \\ Newton Celio Becker de Moura \\ Clara de Oliveira Juca Machado
}

\section{RESUMO}

A Avenida Aguanambi, situada na cidade de Fortaleza, CE, é conhecida pela suscetibilidade a alagamentos em períodos chuvosos. A infraestrutura verde é uma importante alternativa para complementar a convencional e consolidar a resiliência urbana nas vias. Com o objetivo principal de propor a implantação de corredores verdes no sistema viário de Fortaleza, $\mathrm{CE}$, foi desenvolvido um método de análise do desempenho das melhores práticas de manejo em corredores de mobilidade. As técnicas de manejo foram distribuídas com base na hierarquia viária estabelecida pela Lei de Parcelamento, Uso e Ocupação do Solo. A precipitação admitida para a cidade foi de $65,2 \mathrm{~mm} / \mathrm{h}$ com tempo de retorno de dez anos. As biovaletas apresentaram melhor desempenho em vias expressas e arteriais, de maior porte; os jardins de chuva e canteiros pluviais responderam melhor em vias coletoras e locais, consideradas de menor porte.

Palavras-chave: Infraestrutura Verde. Resiliência Urbana. Melhores Práticas de Manejo. Corredores Verdes.

\section{ABSTRACT}

Aguanambi Avenue is in the city of Fortaleza, CE, and it is susceptible to flooding on rainy season. Green infrastructure is an important alternative to complement conventional infrastructure and consolidate urban resilience. With the main goal to propose the greenway's implementation in Fortaleza's road system, this research has developed a method to analyze the performance of Best Management Practices in mobility corridors. The proposal has distributed management techniques according to the road hierarchy established by the Land Use and Occupancy Law. The precipitation volume admitted is $65.2 \mathrm{~mm} / \mathrm{h}$, with 10-year return time. The bioswales had better performance in express and arteria streets, with greater size; the rain gardens and flowerbeds responded better in collectors and local roads, considered of smaller size.

Keywords: Green Infrastructure. Urban Resilience. Best Management Practices. Greenways. 


\section{INTRODUÇÃO}

As cidades foram construídas sobre uma paisagem natural. Fortaleza, como muitas metrópoles brasileiras, teve sua expansão urbana às custas da degradação de vários recursos naturais, como rios, lagoas, dunas e manguezais (NETO; ALBUQUERQUE, 2014).

A infraestrutura cinza ou convencional, definida por sistemas construídos nas cidades para viabilizar o abastecimento de água e energia, a captação de águas pluviais, o saneamento básico, o sistema viário e tudo aquilo que dá suporte ao funcionamento dos assentamentos humanos, provocou a segregação das áreas naturais e acarretou diversos problemas ambientais às cidades, tais como a poluição dos recursos hídricos, os deslizamentos, as enchentes e a alteração do microclima com a formação das ilhas de calor (BONZI, 2017). Dessa forma, entende-se que as políticas públicas adotadas em Fortaleza ainda são baseadas em soluções do século passado, conforme afirma Bonzi:

Sob o pretexto do higienismo e capitulado pela engenharia civil, o planejamento urbano do século XX imaginou ser possível prescindir da cobertura vegetal e dos recursos naturais enquanto soluções tecnicistas driblaram o ciclo hidrológico. Solos foram impermeabilizados, aumentando o escoamento superficial da água da chuva, e linhas de drenagem naturais foram substituídas por galerias pluviais projetadas para conduzir as águas de forma rápida e invisível, expediente sinistro que transfere o volume indesejado de água para uma comunidade mais à jusante. (BONZI, 2017, p. 2).

Corroborando a constatação de que esse tipo de solução é adotado a priori nas obras públicas da capital cearense, a Prefeitura Municipal de Fortaleza está construindo estações acima do riacho Água Nambi para abrigar o sistema de transporte Bus Rapid Transit (BRT). Dessa forma, mais um recurso hídrico da cidade será sepultado. A obra, orçada em 95 milhões de reais (FORTALEZA, 2017b), está promovendo o tamponamento de $36 \%$ da superfície do canal e a construção de uma galeria auxiliar para a captação de águas pluviais. Conforme a Prefeitura de Fortaleza:

Orçada em R\$ 95 milhões, com o viaduto e passarela liberados em março deste ano, as obras foram iniciadas em fevereiro de 2016 e fazem parte do corredor expresso Messejana/Centro, que prevê diversas intervenções na região, como a requalificação viária da Avenida Aguanambi, com a implantação de um novo sistema de drenagem, calçadas, quatro quilômetros de ciclovia, instalação de oito estações de ônibus junto ao canteiro central, além da urbanização e reforma de duas praças e da rotatória existente sob o novo viaduto. A segunda etapa da obra, que prevê a ampliação de urbanização da Av. Aguanambi, possui conclusão prevista para janeiro de 2018 (FORTALEZA, 2017b).

Diante desse fato, a intervenção na Avenida Aguanambi demonstra que a aplicação da infraestrutura cinza foi a principal solução de projeto admitida para viabilizar a implantação do corredor de BRT.

Notícias de alagamentos na avenida citada comprovam o impacto das intervenções mal planejadas das últimas décadas que não consideraram as características naturais do sítio, tais como a topografia, o recurso hídrico e suas várzeas. Em 8 de janeiro de 2017 ocorreu no período da manhã uma precipitação de 55,6 $\mathrm{mm}$, que causou o transbordamento do canal da Aguanambi (COM..., 2017) (Figura 1). Tecnicamente, isso significa que na área de $1 \mathrm{~m}^{2}$ formou-se uma lâmina de $55,6 \mathrm{~mm}$ ou $5,5 \mathrm{~cm}$ de altura. Pode parecer pouco, mas em regiões vulneráveis, como a Aguanambi, as consequências desse tipo de evento climático são desastrosas.

Portanto, diante dessas informações, o problema identificado é a vulnerabilidade do sistema viário da cidade de Fortaleza a eventos naturais, como precipitações intensas, situação provocada pelo adensamento urbano (BONZI, 2015) e pelas intervenções promovidas ao longo dos anos para melhorar a mobilidade urbana, acarretando intensa impermeabilização do solo. 


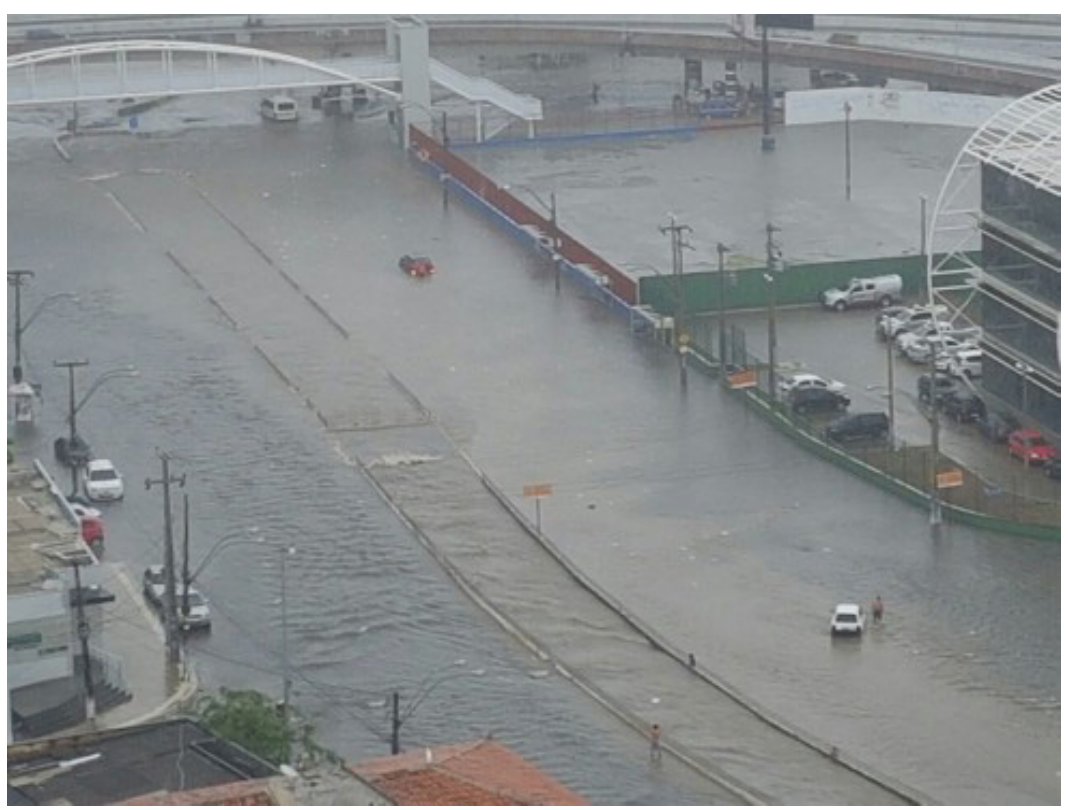

Figura 1 - Canal da Aguanambi transbordado em dia chuvoso. Fonte: G1 CE, 2017.

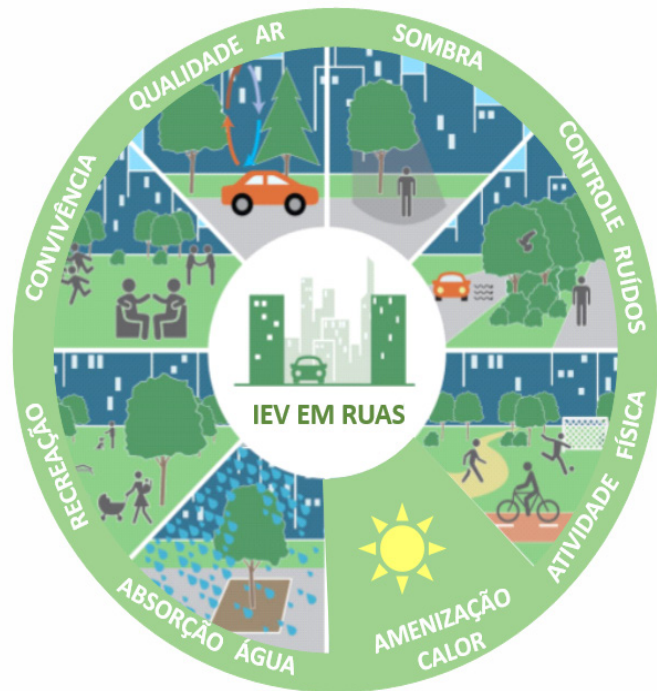

Figura 2 - Benefícios da implantação de infraestrutura verde nas ruas. Fonte: Gehrels et al. (2016).
As intervenções adaptativas nas cidades são essenciais para a resiliência urbana, mas somente se aplicadas através de sistemas baseados na ecologia (CHELLERI et al., 2015). A infraestrutura verde (IEV) é definida como uma rede de áreas verdes interconectadas que promove uma série de benefícios ambientais como a regulação do clima e a preservação da biodiversidade (BENEDICT; MCMAHON, 2006). O desenvolvimento de baixo impacto (DBI), traduzido de low impact development, desenvolveu-se nos últimos anos como uma das principais alternativas para a constituição de uma IEV nos espaços públicos e privados através da aplicação de técnicas de manejo das águas pluviais; também conhecidas como melhores práticas de manejo (MPM), termo traduzido de best practices management. De acordo com Gehrels et al. (2016) a IEV aplicada em ruas e avenidas, através das MPM, pode oferecer inúmeros serviços ecológicos que contribuam para a resiliência urbana (Figura 2).

A consolidação de corredores verdes no sistema viário através das MPM pode promover a conexão entre os polos ecológicos, configurando uma IEV, a qual desempenha um papel importante na efetivação dos serviços ambientais de provisão, apoio e purificação (HUBER et al., 2010).

O objetivo desta pesquisa consiste no desenvolvimento de diretrizes para orientar a formação de uma rede de corredores verdes através dos corredores de mobilidade de Fortaleza, com a ampliação da distribuição das técnicas de manejo de águas pluviais de uma escala local para a escala municipal (Figura 3). Essas orientações se adequam aos parâmetros estabelecidos pela nova Lei de Parcelamento, Uso e Ocupação do Solo (Luos) do município de Fortaleza para o sistema viário da cidade. 


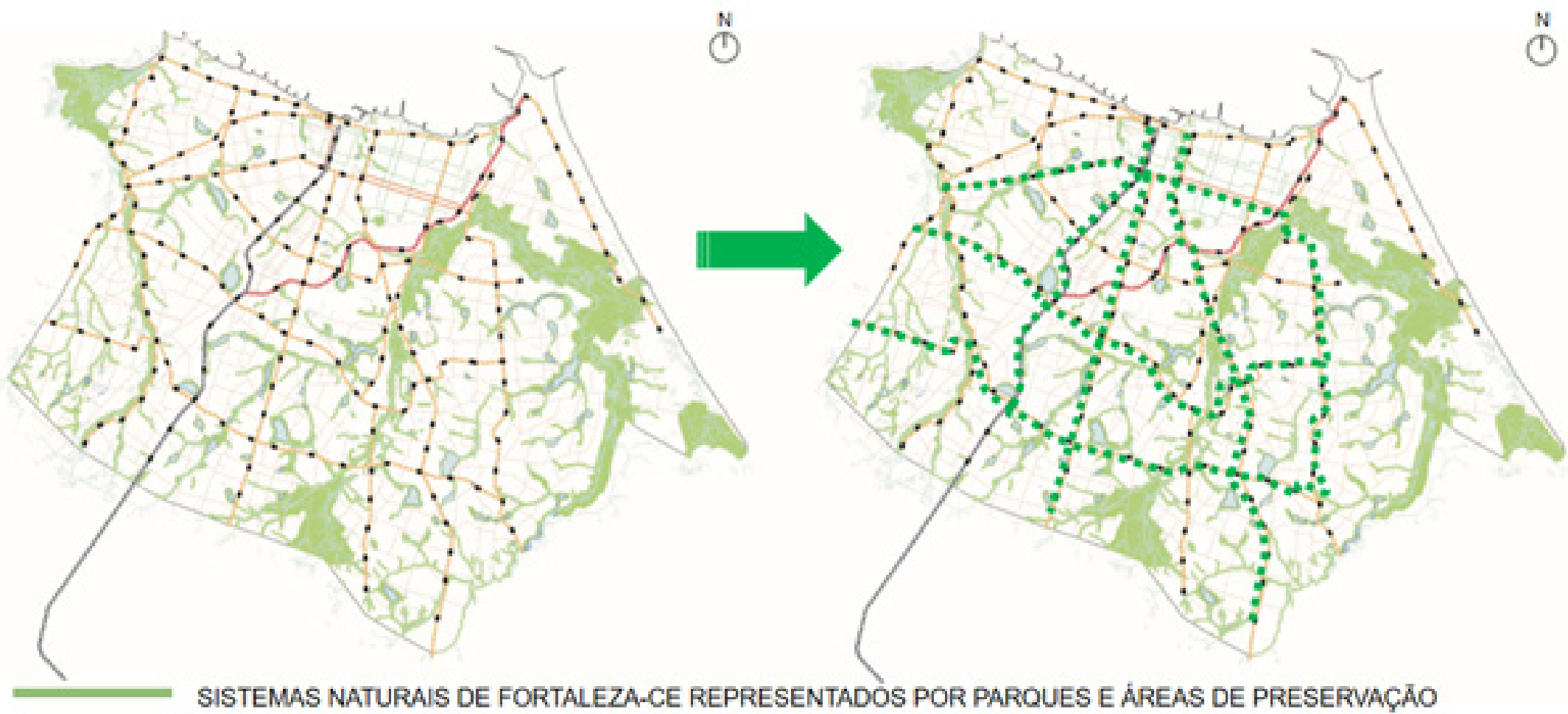

\section{RECURSOS HIDRICOS DE FORTALEZA-CE REPRESENTADOS POR LAGOAS, RIACHOS E RIOS}

$n=n=n=$ " $=$ SISTEMA VIÁRIO ADAPTADO AOS CORREDORES VERDES

Figura 3 - Adaptação do sistema viário aos corredores verdes.

Fonte: adaptado de Fortaleza 2040 (2015) 


\section{Revisão de Literatura Sobre a Relação do Sistema Viário com os Corredores Verdes, e a Aplicabilidade das Melhores Práticas de Manejo em Corredores de Mobilidade}

De acordo com Little (1990) e Yu, Li e Li (2006), corredor verde é um espaço livre linear arborizado ao longo de um corredor natural, ou seja, de rios, da costa marítima, de um vale ou de estradas ou vias convertidas em áreas para recreação e lazer, como uma via paisagística ou rio canalizado. Little (1990) também define o conceito em análise como um corredor de mobilidade arborizado voltado para a circulação de pedestres e ciclistas, atuando como um conector entre praças, parques, reservas naturais e sítios históricos.

Essas conexões verdes são peças fundamentais do planejamento urbano; e a disseminação dessa solução representa um grande potencial para a recuperação dos recursos naturais nas cidades, estados ou países (FABOS, 1995). Esses corredores podem ter diferentes larguras e se comportam como uma rede conectada e direcional, assim como ruas, avenidas ou estradas. A principal diferença entre os corredores verdes naturais e os artificiais é que nos primeiros a natureza é a principal infraestrutura e a sua rede de conexões é considerada pré-existente (FABOS, 1995).

Conforme Yu, Li e Li (2006), corredores verdes ao longo de rios, canais ou córregos vêm provando a importância da implantação da arborização nas margens desses recursos hídricos como uma forma eficaz para a prevenção de alagamentos. Os chineses, assim como outros povos ao redor do mundo, sofrem bastante por causa dos transbordamentos dos rios, por isso surgiu o movimento de criação e preservação de áreas verdes nas margens ribeirinhas com o objetivo de melhorar o sistema de drenagem no entorno desses locais.

Nesta pesquisa foi elaborado um levantamento das funções atribuídas aos corredores verdes pelos principais autores que discutiram o tema nas duas últimas décadas (Quadro 1).
O Quadro 1 mostra que dois dos autores listados descrevem os corredores verdes como elementos fundamentais para a composição de uma infraestrutura verde; e, segundo Benedict e Mcmahon (2006), a IEV se compõe pela conexão entre polos e fragmentos. Yu, Li e Li (2006) e Little (1990) estabelecem uma relação entre os corredores verdes e os eixos de transporte e mobilidade, representados por ruas, avenidas e estradas.

A constituição de corredores verdes no sistema viário se baseia na compatibilidade de algumas técnicas das MPM com os eixos de mobilidade. De acordo com Portland (2016) as seguintes MPM são mais apropriadas para aplicação em ruas, avenidas e estradas:

- Biovaletas

- Jardins de chuva

- Canteiros pluviais

- Sarjetas verdes

- Canteiros arborizados

- Pavimentos permeáveis

As características e especificidades das MPM influenciam a definição de sua localização no sistema viário, pois cada uma tem dimensões mínimas e requisitos específicos para desempenhar corretamente suas funções (PRINCE GEORGE, 1999; HUBER et al., 2010; PORTLAND, 2016). Uma investigação mais aprofundada apresenta as atribuições dessas composições paisagísticas para a realização dos serviços ambientais. 


\section{Quadro 1 - Estudo comparativo de funções atribuídas aOS CORREdores Verdes.}

\begin{tabular}{c|l}
\hline Autores & \multicolumn{1}{c}{ Funçães dos corredores verdes } \\
\hline \multirow{3}{*}{ Little (1990) } & $\begin{array}{l}\text { - Recuperação de espaços livres com a criação dos corredores verdes ao longo de recursos hídricos } \\
\text { negligenciados, como rios ou as frentes marítimas. } \\
\text { - Recreação através de caminhos e trilhas ao longo de vias férreas desativadas ou rios canalizados. } \\
\text { - Preservação de corredores naturais para garantir a conectividade entre as espécies, a manutenção da fauna } \\
\text { e flora, o desenvolvimento de estudo e atividades físicas para população como caminhadas. } \\
\text { - Facilitar o acesso de pedestres às rotas históricas e culturais. } \\
\text { - Oportunidade para viabilizar a implantação de infraestrutura verde em escala municipal ou regional. }\end{array}$ \\
\hline Fabos (1995) & $\begin{array}{l}\text { - Criação de corredores ecológicos e sistemas ao longo de rios e da costa marítima, para a preservação de } \\
\text { fauna e flora. } \\
\text { - Estabelecimento de corredores voltados para o lazer e recreação, através da valorização da paisagem em } \\
\text { áreas urbanas ou rurais e com diferentes escalas de aplicação (local, regional, nacional ou internacional). } \\
\text { - Valorização histórica e cultural voltada para o turismo com o objetivo de promover atividades educativas, } \\
\text { de lazer e desenvolvimento econômico e social. }\end{array}$ \\
\hline Yu, Li e Li, (2006) & $\begin{array}{l}\text { - Prevenção de enchentes ao logo de rios e canais. } \\
\text { - Criação de áreas sombreadas, de abrigo e de melhoria da drenagem ao longo de ruas, estradas e rodovias. }\end{array}$ \\
\hline Benedict e & $\begin{array}{l}\text { - Recreação e saúde para as pessoas. } \\
\text { - Realçar o valor histórico e cultural nas comunidades. } \\
\text { - Permite o estabelecimento de uma rede de infraestrutura verde por meio da conexão de fazendas, ranchos } \\
\text { e florestas. }\end{array}$ \\
\hline
\end{tabular}


É importante compreender as funções relativas à infiltração', evapotranspiração ${ }^{2}$ e fitorremediação ${ }^{3}$, três atributos essenciais no desempenho das MPM para a implementação dos serviços ecológicos.

\subsection{Caracterização das Melhores Práticas de Manejo}

Após a introdução dos atributos gerais das MPM, cabe apresentar as especificidades de biovaletas, jardins de chuva, canteiros pluviais, sarjetas verdes, canteiros arborizados e pisos permeáveis com o intuito de elaborar diretrizes para sua implantação no sistema viário de Fortaleza.

\subsubsection{Biovaletas}

Biovaletas são canais de vegetação abertos, de inclinação suave, projetados para transportar o escoamento de águas pluviais, eliminando a necessidade de sistemas de drenagem convencionais dispendiosos. A principal função da biovaleta é tratar o escoamento da água da chuva à medida que é transportado; o tratamento ocorre através da infiltração. As biovaletas geralmente são localizadas ao longo de estradas, ruas largas e estacionamentos (Figura 4) e requerem dispositivos de apoio para direcionarem o fluxo das águas e manejarem o volume excedente (HUBER et al. 2010).

1 Infiltração é o processo de percolação da água no solo e pode acontecer de forma variável, dependendo do tipo de solo e da quantidade de umidade já existente nele. A água pode chegar até o lençol freático ou fluir horizontalmente próximo à superfície até um curso d'água. Nesse percurso, uma porção da água é absorvida pela vegetação (UNITED STATES, 2004).

2 Evapotranspiração é a perda de água do solo por evaporação e transpiração. A evaporação é o retorno da umidade à atmosfera através das plantas; essa umidade é absorvida do solo pelas raízes e liberada através das folhas. A taxa de evapotranspiracão depende do ar temperatura, umidade, velocidade do vento, intensidade da luz solar, tipo de vegetação e condições do solo (UNITED STATES, 2004).

3 Fitorremediação é nome da tecnologia que utiliza os processos naturais das plantas e suas interações com a microbiota na despoluição dos ambientes. Tem sido referida como o método mais rentável, não invasivo e publicamente aceito no tratamento de ambientes contaminados (RUBY; APPLETON, 2010 apud PINHEIRO, 2017).
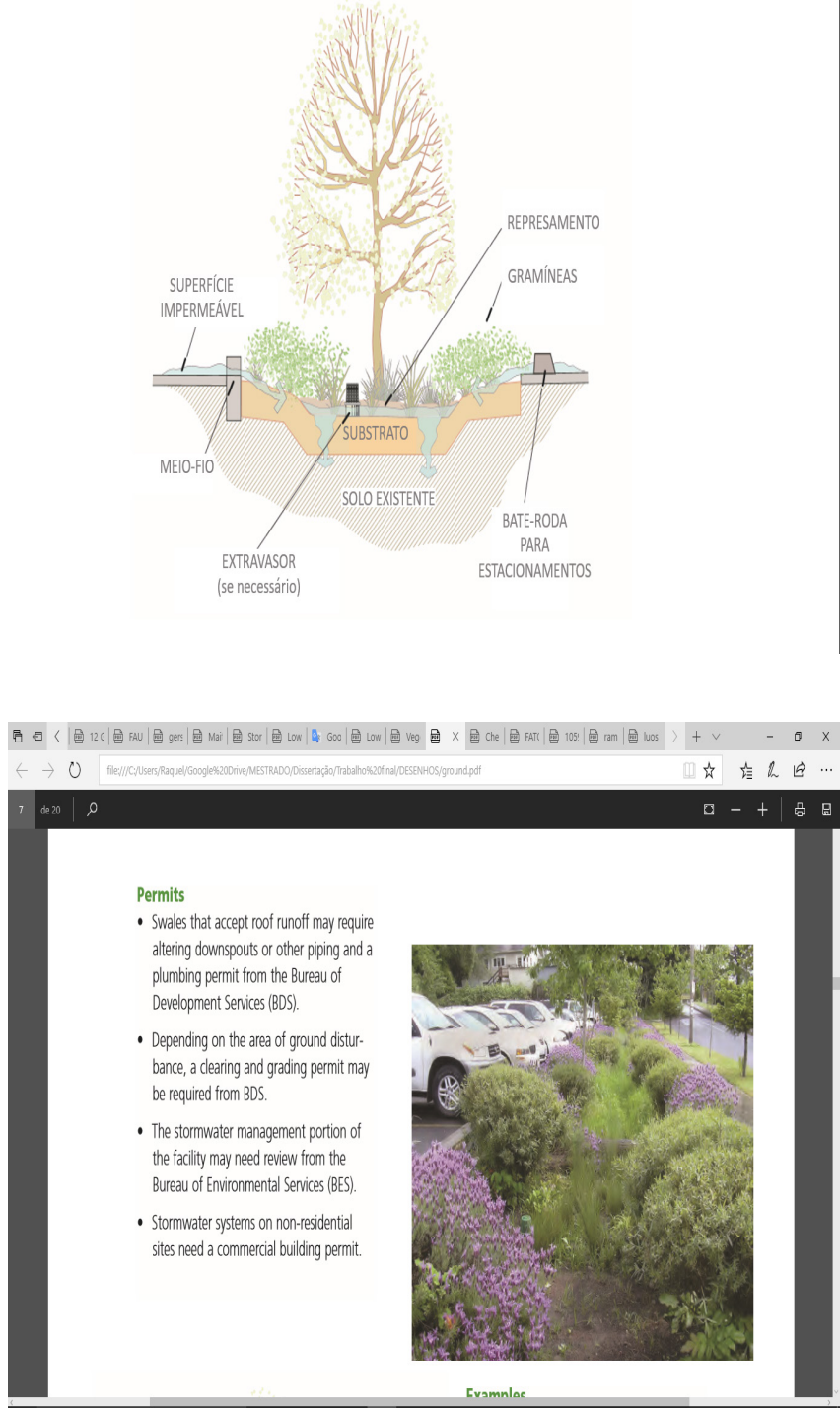

Figura 4 - Biovaletas.

Fonte: adaptado de Portland ([201-]). 
De acordo com Cormier e Pellegrino (2008, p. 132) "cabe aos jardins de chuva fazerem a maior parte do trabalho de infiltração no solo, mas a biovaleta também contribui, filtrando os poluentes trazidos pelo escoamento superficial ao longo de seu substrato e da vegetação implantada". As biovaletas podem ser excelentes substitutas do sistema de drenagem convencional, principalmente quando este se torna obsoleto por causa do aumento do runoff, muitas vezes provocado pela intensa impermeabilização do solo. Com essas valetas naturais cumprindo seu papel, a infraestrutura convencional pode funcionar como backup das águas excedentes durante chuvas intensas (BONZI, 2015).

\subsubsection{Jardins de Chuva}

Um jardim de chuva é uma depressão vegetada que serve para infiltrar, mas não reter o runoff, também conhecido como um sistema de biorretenção (Huber et al., 2010). Os jardins de chuva combinam camadas de solo arenoso orgânico e substrato para plantas nativas são recomendadas com base em suas sinergias intrínsecas com clima local, solo e condições de umidade sem o uso de fertilizantes e produtos químicos (BONZI, 2015). De acordo com Bonzi (2015), esses canteiros vegetados podem promover os seguintes serviços ecológicos:

- Redução de poluentes transportados pelas águas da chuva através de processos de fitorremediação, pois o escoamento passa pela comunidade de plantas e pelo solo;

- Formação de pequenos habitats naturais;

- Aumento da umidade do ar por causa do processo de evapotranspiração relacionado ao metabolismo das plantas.

- Os jardins de chuva são melhor aplicados em uma escala relativamente pequena e funcionam bem ao longo de calçadas e em áreas baixas (Figura 5). Sua localização deve ser a pelo menos três metros de distância das
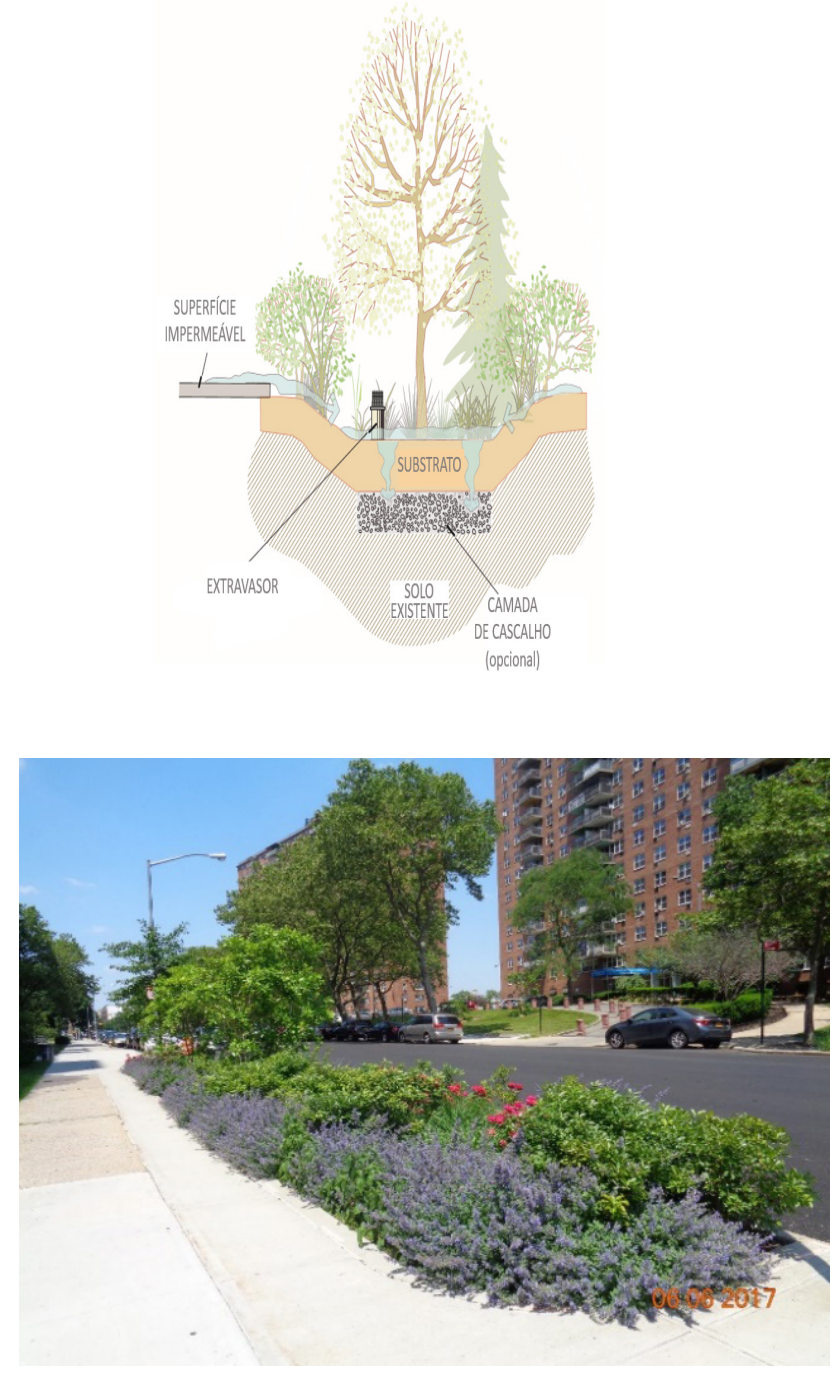

Figura 5 - Jardins de Chuva.

Fonte: adaptado de Portland ([201-]) (esquerda); acervo pessoal da autora (direita). 

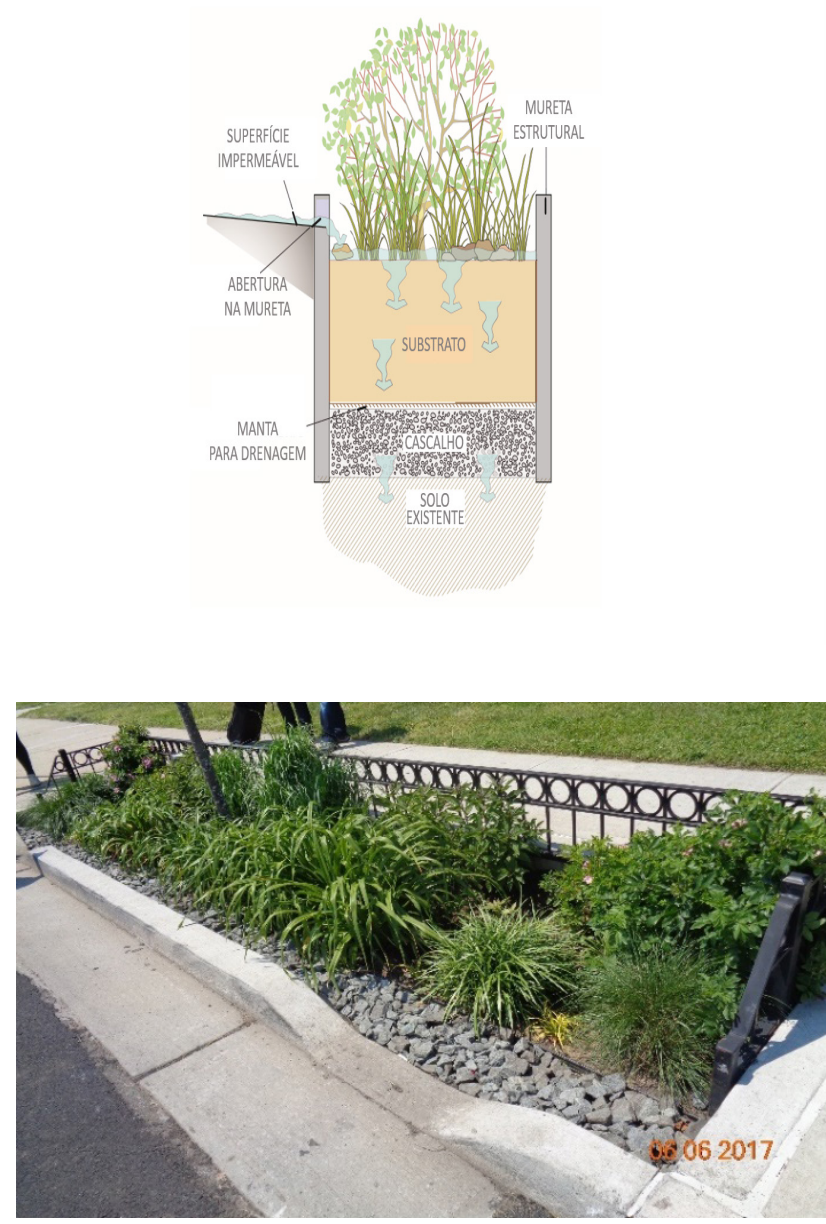

Figura 6 - Canteiro pluvial.

Fonte: adaptado de Portland ([201-]) (esquerda); acervo pessoal da autora (direita). edificações para evitar infiltração de água nas fundações ou embaixo das casas, causando problemas de umidade (PRINCE GEORGE, 1999). Localizá-los longe de árvores grandes permite a exposição à luz solar para que os jardins possam secar no período entre as precipitações (Huber et al., 2010).

Sobre a implantação dessa técnica de manejo, "o correto dimensionamento de um jardim de chuva deve atentar também para o fato que, algumas horas depois de um evento, não deve existir água parada em sua superfície" (CORMIER; PELLEGRINO, 2008, p. 129). "Os jardins de chuva devem possuir mecanismos de extravasamento para suportar precipitações mais intensas." (BONZI, 2015, p. 108)

\subsubsection{Canteiros Pluviais}

Os canteiros pluviais são como jardins de chuva compactos, indicados para espaços urbanos reduzidos (Figura 6), e não têm necessariamente a função de infiltração como os jardins de chuva, mas realizam a limpeza da água através da fitorremediação, e a evapotranspiração; extravasores de água podem auxiliar os canteiros com capacidade de infiltração (CORMIER; PELLEGRINO, 2008). Os critérios para definição da vegetação são os mesmos utilizados nos jardins de chuva, e quando não há infiltração é interessante a indicação de espécies com elevadas taxas de evapotranspiração para evitar o acúmulo de água parada (PINHEIRO, 2017).

\subsubsection{Sarjetas Verdes}

As sarjetas verdes, também conhecidas como extensões de calçada (termo traduzido de curb extension), são tipicamente usadas em situações de adaptação para gerenciar o runoff. Elas podem criar locais para o manejo das águas da chuva quando o espaço da calçada existente é constrangido ou inadequado. Elas interceptam e enviam as águas pluviais da rua para instalações suavemente inclinadas similares a jardins de chuva. Dentro da 

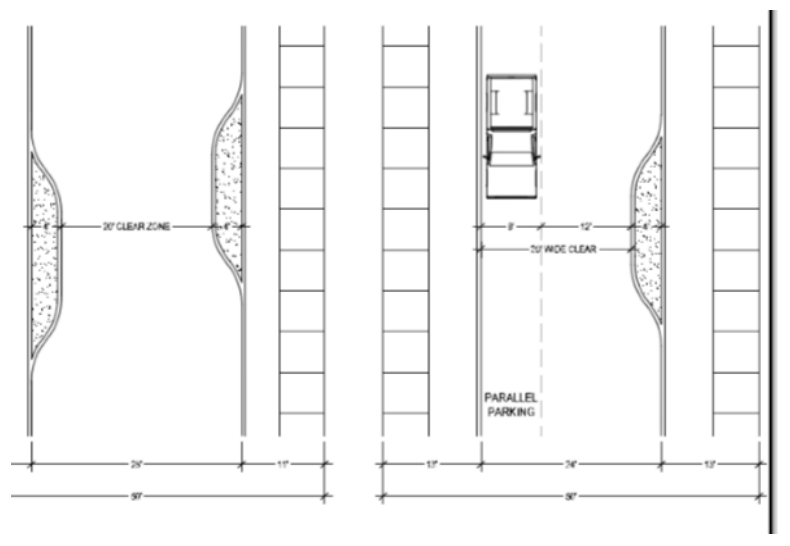

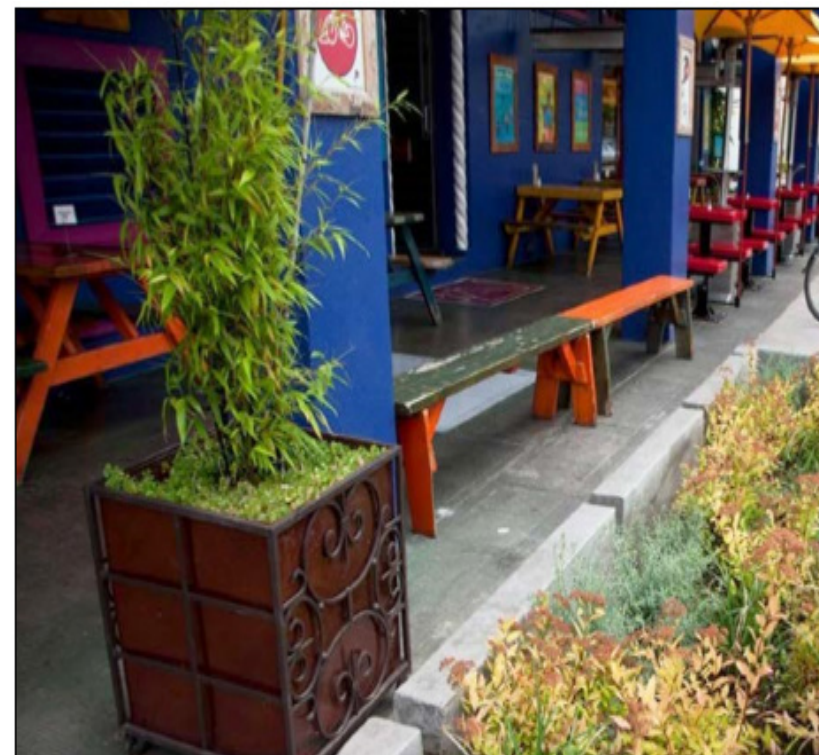

Figura 7 - Sarjetas verdes são áreas de paisagem do lado da rua que armazenam, filtram e infiltram o escoamento de águas pluviais. Fonte: Portland (2016). instalação, a vegetação e as barreiras de controle retardam o escoamento, filtram, e, na maioria das vezes, permitem a sua infiltração no solo (SEMCOG, 2008).

Essa tipologia de MPM pode melhorar, através do seu desenho curvo, a segurança de motoristas, pedestres e ciclistas, reduzindo a distância de cruzamentos, e promovendo a redução da velocidade dos automóveis (PORTLAND, 2016). Segundo Bonzi (2015), a sinuosidade das extensões de calçadas interfere positivamente no sistema viário, criando o traffic calming e revertendo a prioridade dos veículos sobre os pedestres baseada na insegurança (Figura 7) (BONZI, 2015).

\subsubsection{Canteiros Arborizados}

O canteiro arborizado consiste em um pequeno espaço cheio de solo modificado e plantado com uma árvore. As raízes da árvore tratam e absorvem o runoff capturado da rua para o canteiro. Arbustos resistentes e plantas herbáceas tolerantes a inundações também podem ser cultivadas nesse espaço (HUBER et al., 2010). Esses canteiros (Figura 8) podem ser incorporados em intervenções urbanas para promover diversos benefícios ambientais (HUBER et al. 2010; PORTLAND, 2016):

- Melhoria da qualidade da água;

- Redução do efeito de ilha de calor;

- Diminuição da absorção de calor pelo pavimento impermeável;

- Redução do aquecimento das águas pluviais que fluem por essa superfície.

\subsubsection{Pavimento Permeável}

O sistema de pavimentação permeável é suportado por camadas subterrâneas de solo, cascalho e areia para aumentar o armazenamento e maximizar as taxas de infiltração da chuva. Consiste em técnicas de redução de áreas impermeáveis que contribuem para a diminuição do runoff e promovem a 

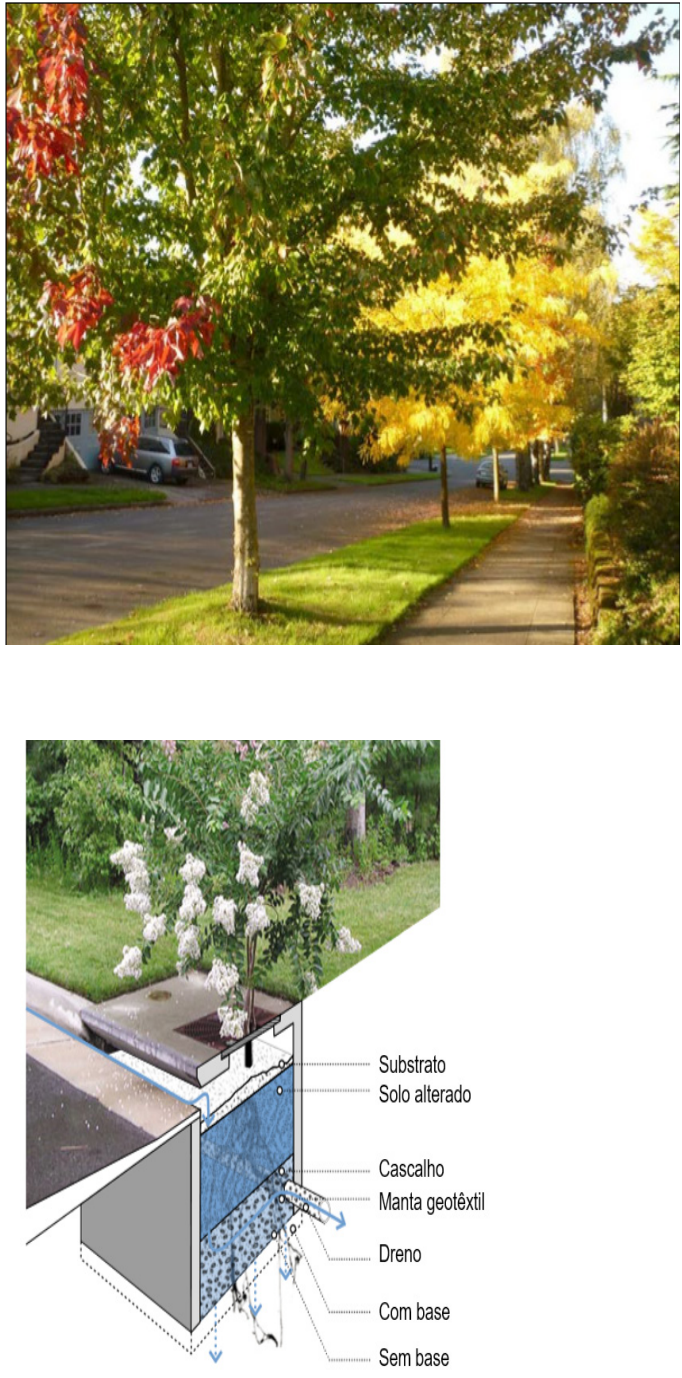

Figura 8 - Canteiros arborizados Fonte: adaptado de Huber et al. (2010 p. 177) (esquerda); Portland (2016 p. 2-53) (direita). absorção de parte das águas pluviais no local da precipitação (PORTLAND, 2016). Esse tipo de pavimento reduz e distribui o volume do escoamento, promovendo a remoção de poluentes e incentivando o abastecimento das camadas subterrâneas (HUBER et al., 2010).

De acordo com Portland (2016), asfalto permeável, concreto poroso e outros revestimentos permeáveis podem ser usados em praticamente todas as áreas para pedestres, bem como calçadões residenciais e estacionamentos. Para as ruas, o design e o tipo do pavimento deve ser planejado e especificado por engenheiro ou arquiteto. A redução do efeito da ilha de calor é possível ao usar materiais com superfícies que não aquecem com a irradiação solar (HUBER et al., 2010).

O piso permeável (Figura 9) é mais susceptível a dificuldades e falhas durante a construção, portanto, é importante que sua aplicação seja realizada adequadamente para prevenir problemas no futuro (SEMCOG, 2008). Para a eficácia desse tipo de material, é importante definir sua localização corretamente, pois existem tipos de solo com baixa capacidade de absorção. A realização de manutenção periódica é fundamental para o seu bom desempenho (BONZI, 2015).

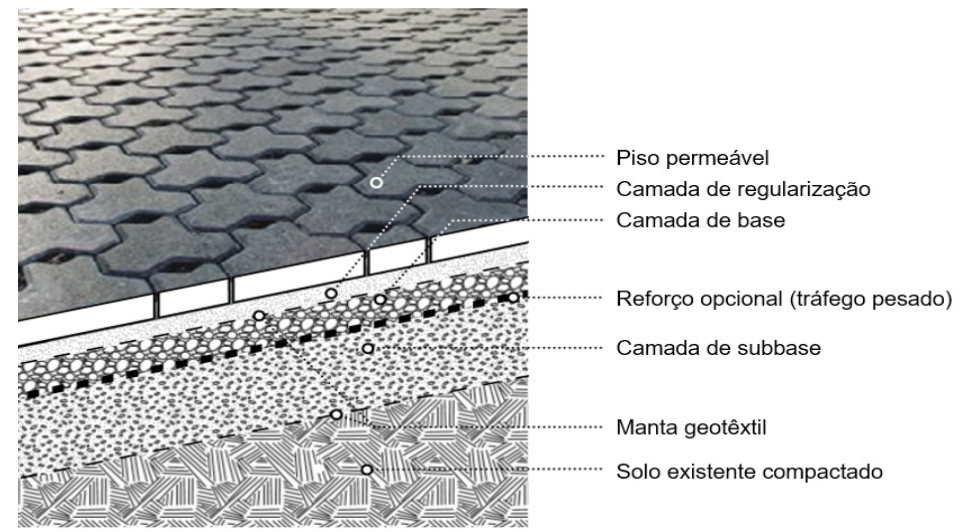

Figura 9 - Pavimento permeável. Fonte: adaptado de Huber et al. (2010, p. 173) 


\section{Metodologia}

Para encontrar o volume de chuva, dimensionar e distribuir as MPM no sistema viário, e definir o seu volume de retenção, foi necessário coletar e indicar alguns dados:

- Tempo de retorno em anos a ser aplicado;

- Intensidade da maior precipitação;

- Coeficiente de escoamento superficial (runoff);

- Dimensões e localização das MPM;

- Volume de retenção das MPM.

\subsection{Definição do Tempo de Retorno e da Maior Intensidade de Chuva}

O tempo de retorno é o espaço temporal determinado para o dimensionamento de obras de microdrenagem e macrodrenagem (SILVA; PALÁCIO JÚNIOR; CAMPOS, 2013), que consiste na previsão da maior chuva que pode ocorrer dentro de um período que geralmente varia de 5 a 100 anos. Para alcançar os resultados a respeito da eficiência das MPM, foi fundamental encontrar o volume de chuva precipitado na área de estudo, o qual depende do tempo de retorno estabelecido para projetos de implantação dessas técnicas de manejo que, conforme Portland (2016), é de dez anos, de acordo com as categorias 1 e 2 descritas no Quadro 2. Esse período é indicado para garantir a eficiência dos projetos em curto, médio e longo prazos.

\section{QUAdRO 2 - INDICAÇÃO DO TEMPO DE RETORNO A SER ADOTADO PARA A IMPLANTAÇÃO DOS JARDINS DE CHUVA.}

\begin{tabular}{l|l}
\hline \multicolumn{2}{c}{ Requisitos de gerenciamento de águas pluviais } \\
\hline \multicolumn{1}{c|}{ Tipos de técnicas de manejo das águas pluviais } & \multicolumn{1}{c}{$\begin{array}{c}\text { Requisito de gerenciamento de águas pluviais } \\
\text { baseado no tempo de retorno (TR) }\end{array}$} \\
\hline $\begin{array}{l}\text { Redução de área impermeável com tetos verdes, pisos permeáveis } \\
\text { e arborização. }\end{array}$ & Não há requisitos adicionais para esse tipo de técnica de manejo \\
\hline $\begin{array}{l}\text { Categoria 1: Drenagem através de jardins de chuva sem } \\
\text { extravasão }\end{array}$ & Precipitação para um tempo de retorno de 10 anos. \\
\hline $\begin{array}{l}\text { Categoria 2: Drenagem através de jardins de chuva ou pavimento } \\
\text { permeável com extravasão e instalação para infiltração } \\
\text { (tubulação subterrânea). }\end{array}$ & $\begin{array}{l}\text { Precipitação para um tempo de retorno de } 10 \text { anos e atendimento } \\
\text { dos requisitos de controle da infiltração subterrânea. }\end{array}$ \\
\hline $\begin{array}{l}\text { Categoria 3: Drenagem através de jardins de chuva com } \\
\text { extravasão para rede de drenagem existente ou recurso hídrico }\end{array}$ & $\begin{array}{l}\text { Precipitação para um tempo de retorno que pode variar entre 2 } \\
\text { e 25 anos. }\end{array}$ \\
\hline $\begin{array}{l}\text { Categoria 4: Drenagem através de jardins de chuva com } \\
\text { extravasão para sistema combinado de esgoto e drenagem }\end{array}$ & $\begin{array}{l}\text { Precipitação para um tempo de retorno que pode variar entre 10 } \\
\text { e 25 anos. }\end{array}$ \\
\hline
\end{tabular}

Fonte: Portland (2016). 
Portanto, dez anos será o valor indicado do tempo de retorno para o cálculo da intensidade da chuva. Vale ressaltar que esse tempo e o índice pluviométrico adotados são recomendados para projetos de obras de microdrenagem urbana em pequenas bacias de drenagem (inferior a 2,5 $\mathrm{km}^{2}$ ) na cidade de Fortaleza e sua região metropolitana (SILVA; PALÁCIO JÚNIOR; CAMPOS, 2013). $\mathrm{Na}$ Tabela 1 encontram-se os valores estimados da intensidade máxima provável de chuva $(\mathrm{mm} / \mathrm{h})$ para a capital cearense durante 60 minutos, com tempo de retorno de 5 a 100 anos

TABELA 1 - INTENSIDAde MÁXIMA PROVÁVEL PARA UMA CHUVA de 60 Minutos em Fortaleza e REGIÃo METROPOLITANA.

\begin{tabular}{c|c|c|c|c|c|c|c}
\hline \multicolumn{7}{c}{ Intensidade máxima provável (mm/h) } \\
\hline $\begin{array}{c}\text { Duração } \\
\text { (minu- } \\
\text { tos) }\end{array}$ & $\begin{array}{c}5 \\
\text { anos }\end{array}$ & $\begin{array}{c}10 \\
\text { anos }\end{array}$ & $\begin{array}{c}15 \\
\text { anos }\end{array}$ & $\begin{array}{c}20 \\
\text { anos }\end{array}$ & $\begin{array}{c}25 \\
\text { anos }\end{array}$ & $\begin{array}{c}50 \\
\text { anos }\end{array}$ & $\begin{array}{c}100 \\
\text { anos }\end{array}$ \\
\hline 60 & 55,4 & 65,2 & 70,6 & 74,5 & 77,5 & 86,6 & 95,6 \\
\hline
\end{tabular}

Fonte: Silva, Palácio Júnior e Campos (2013).

O valor de $65,2 \mathrm{~mm} / \mathrm{h}$ será multiplicado pela área definida e pelo seu escoamento superficial com o objetivo de definir o volume de chuva através do método racional $\mathrm{V}=\mathrm{A} \times \Delta \mathrm{p} \times$ runoff (LIMA, 2016).

Onde:

V é o volume de chuva a ser encontrado.

$\Delta \mathbf{p}=$ intensidade pluviométrica de $65,2 \mathrm{~mm} / \mathrm{h}$ (SILVA; PALÁCIO JÚNIOR; CAMPOS, 2013).

Runoff é o coeficiente de escoamento superficial que pode variar de 0 a 1 (ARAÚJO; ALMEIDA; GUERRA, 2005).

\subsection{Avaliação do Desempenho das Melhores Práticas de Manejo a Partir dos Padrões Estabelecidos na Lei de Parcelamento, Uso e Ocupação do Solo}

Nesta seção, o desempenho das MPM aplicáveis aos corredores de mobilidade foi avaliado de acordo com os padrões das vias de circulação especificados na Lei de Parcelamento, Uso e Ocupação do Solo (FORTALEZA, 2017a), do município de Fortaleza, CE. Em 2017, a Luos foi revisada e atualizada para regulamentar novas regras de parcelamento e uso do solo de acordo com o novo cenário consolidado nos últimos anos através da expansão urbana.

De acordo com a publicação de Lei Complementar $n^{\circ} 236$, em 2017, "o sistema viário básico de Fortaleza é formado por dois Sistemas: I - Sistema Viário Básico Estrutural; e II - Sistema Viário Básico Complementar" (FORTALEZA, 2017a, p. 20). O sistema estrutural é composto por vias expressas e arteriais I, responsáveis pela articulação viária regional e intramunicipal; o complementar é composto por vias arteriais II, coletoras, comerciais, paisagísticas, locais e corredores turísticos, as quais desempenham o papel de coletar e distribuir o trânsito desde a escala do bairro até a do município através de uma hierarquia (FORTALEZA, 2017a, p. 20) (Quadro 3).

Os seguintes padrões de vias dimensionados pela Luos (2017) foram utilizados para a realização de uma análise da performance das MPM: via expressa, via arterial, via coletora e via local (Tabela 2). 
QuadRo 3 - ClassificaÇÃo dAS VIAS DO SISTEMA VIÁrio pela Lei de Parcelamento, Uso e Ocupação do SOLO.

\begin{tabular}{c}
\hline Classificação das vias do sistema viário \\
\hline Vias expressas \\
\hline Vias arteriais I \\
\hline Vias arteriais II \\
\hline Vias coletoras \\
\hline Vias paisagísticas \\
\hline Vias comerciais \\
\hline Corredores turísticos \\
\hline Vias locais
\end{tabular}

Fonte: Fortaleza (2017).

Tabela 2 - Dimensões estabelecidas para o sistema viário de Fortaleza.

\begin{tabular}{|c|c|c|c|c|c|c|c|c|}
\hline \multirow[b]{3}{*}{ Características } & \multicolumn{8}{|c|}{ Vias para circulação de veículos } \\
\hline & \multicolumn{2}{|c|}{ Expressa } & \multicolumn{2}{|c|}{ Arterial } & \multicolumn{2}{|c|}{ Coletora } & \multicolumn{2}{|c|}{ Local } \\
\hline & $\begin{array}{l}\text { Seção } \\
\text { normal }\end{array}$ & $\begin{array}{l}\text { Seção } \\
\text { reduzida }\end{array}$ & $\begin{array}{l}\text { Seção } \\
\text { normal }\end{array}$ & $\begin{array}{l}\text { Seção } \\
\text { reduzida }\end{array}$ & $\begin{array}{l}\text { Seção } \\
\text { normal }\end{array}$ & $\begin{array}{l}\text { Seção } \\
\text { reduzida }\end{array}$ & $\begin{array}{l}\text { Seção } \\
\text { normal }\end{array}$ & $\begin{array}{l}\text { Seção } \\
\text { reduzida }\end{array}$ \\
\hline Largura mínima $(\mathrm{m})$ & 60,00 & 45,00 & 34,00 & 30,00 & 24,00 & 18,00 & 14,00 & 11,00 \\
\hline Caixa carroçável mínima (m) & 37,80 & 33,00 & 21,00 & 19,00 & 16,00 & 12,00 & 9,00 & 7,00 \\
\hline Calçada mínima $(\mathrm{m})$ & 5,00 & 3,00 & 4,00 & 3,50 & 3,25 & 3,00 & 2,50 & 2,0 \\
\hline Canteiro central mínimo (m) & 9,00 & 4,00 & 5,00 & 4,00 & 1,50 & - & - & - \\
\hline Declividade máxima (\%) & $6 \%$ & $6 \%$ & $8 \%$ & $8 \%$ & $10 \%$ & $10 \%$ & $15 \%$ & $15 \%$ \\
\hline Declividade mínima (\%) & $0,5 \%$ & $0,5 \%$ & $0,5 \%$ & $0,5 \%$ & $0,5 \%$ & $0,5 \%$ & $0,5 \%$ & $0,5 \%$ \\
\hline
\end{tabular}

Fonte: Fortaleza (2017, p. 51) 
Com base nas dimensões determinadas pela Luos (2017) para as diferentes categorias de via, foi proposto um padrão de distribuição das MPM nos corredores de mobilidade, de acordo com o espaço disponível, sem criar impedimentos à circulação de pedestres ou veículos. A extensão de $100 \mathrm{~m}$ foi definida para a realização de uma análise comparativa da capacidade de retenção das MPM nos diferentes padrões de corredores (Quadro 4).

\section{Quadro 4 - Dimensionamento da Área das MPM aplicadas no sistema Viário.}

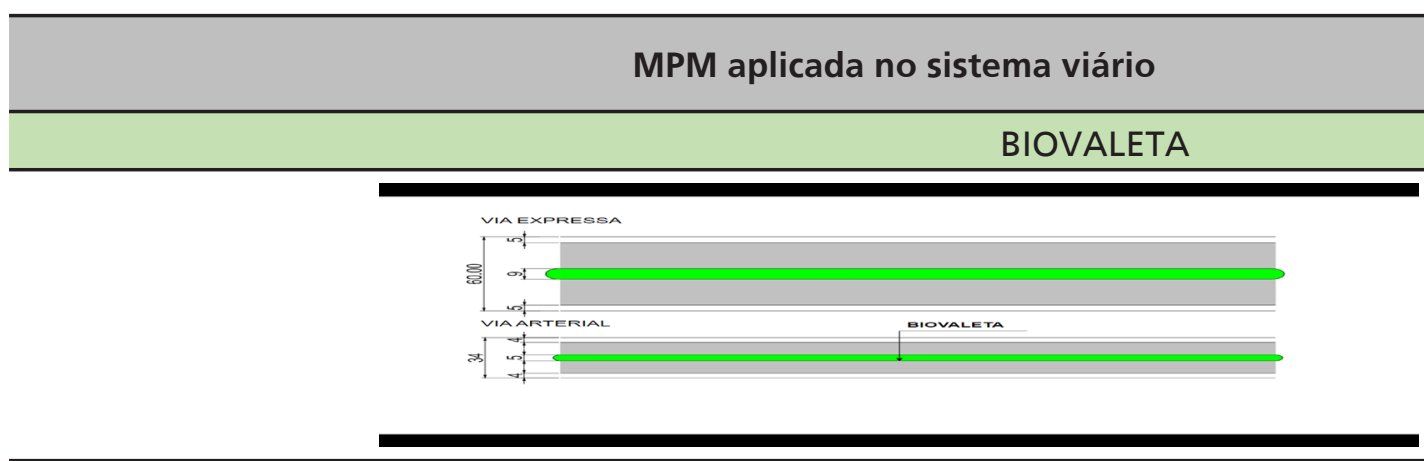

Area MPM $\left(\mathrm{m}^{2}\right)$ a cada $100 \mathrm{~m}$

Indicada para vias com canteiros generosos onde o seu desempenho é melhor, a largura mínima estabelecida foi de $3 \mathrm{~m}$ e por isso, neste estudo, sua aplicação se restringe a vias expressas e arteriais.

\begin{tabular}{l|l|c|}
\hline \multicolumn{2}{|c|}{ JARDIM DE CHUVA } & \\
\hline Os jardins de chuva foram dimensionados com no mínimo $14 \mathrm{~m}^{2}$ (2m de largura máxima por $7 \mathrm{~m}$ de com- \\
primento mínimo), por isso não se inserem em ruas locais onde a calçada pode ter no mínimo 2 ou $2,5 \mathrm{~m}$ \\
(FORTALEZA, 2017a). O modelo proposto disponibiliza espaços de acesso aos lotes para veículos e pedestres.
\end{tabular}




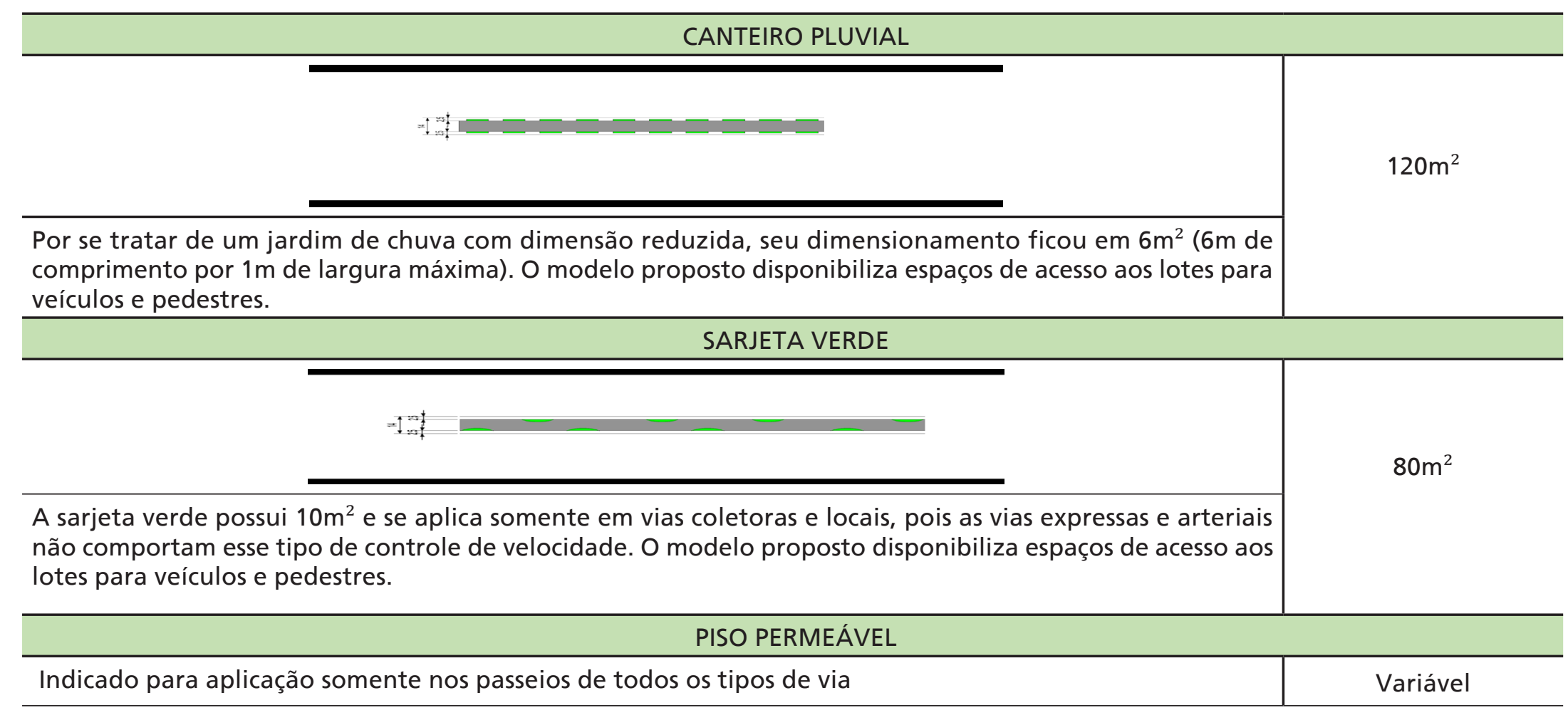

A partir das áreas definidas para as MPM, foi calculado o volume precipitado no recorte espacial de cada via. Nesta análise o valor considerado para o runoff foi baseado no pior cenário, em que o escoamento seria de $100 \%$. Portanto os dados utilizados foram:

- Coeficiente de escoamento superficial (runoff) igual a 1 (ARAÚJO; ALMEIDA; GUERRA, 2014).

Precipitação de $65,2 \mathrm{~mm} / \mathrm{h}(\Delta \mathrm{p})$ para um tempo de retorno de dez anos (TR) (SILVA; PALÁCIO JÚNIOR; CAMPOS, 2013).

- Área dos corredores a cada 100m lineares.
Como as vias possuem diferentes larguras, evidentemente o volume precipitado (V) variou de acordo com cada tipologia (Tabela 3). 
Tabela 3 - Área das Vias a cada $100 \mathrm{~m}$ e volume PRECIPITADO.

\begin{tabular}{c|c|c}
\hline Via & Área $\left(\mathrm{m}^{2}\right)$ & Volume precipitado $\left(\mathrm{m}^{3}\right)$ \\
\hline Local $(\mathrm{L}=14 \mathrm{~m})$ & $1400 \mathrm{~m}^{2}(14 \times 100)$ & $91,28 \mathrm{~m}^{3}$ \\
\hline Coletora $(\mathrm{L}=24 \mathrm{~m})$ & $2400 \mathrm{~m}^{2}(24 \times 100)$ & $156,48 \mathrm{~m}^{3}$ \\
\hline Arterial $(\mathrm{L}=34 \mathrm{~m})$ & $3400 \mathrm{~m}^{2}(34 \times 100)$ & $221,68 \mathrm{~m}^{3}$ \\
\hline Expressa $(\mathrm{L}=60 \mathrm{~m})$ & $6000 \mathrm{~m}^{2}(60 \times 100)$ & $391,2 \mathrm{~m}^{2}$ \\
\hline
\end{tabular}

A partir do cálculo do volume total precipitado e da definição das áreas de MPM a cada 100m de corredor, foi possível realizar a avaliação do desempenho das técnicas nos diferentes corredores do sistema viário de Fortaleza.

Moura (2013) indica que a capacidade de retenção de $1 \mathrm{~m}^{2}$ do jardim de chuva equivale a um volume de retenção de $0,487 \mathrm{~m}^{3}$ $\left(\mathrm{VR} / \mathrm{m}^{2}\right)$, esse número é baseado nos valores da porosidade da brita zero e do macadame hidráulico para um jardim de chuva de $1 \mathrm{~m}^{2}$. Para o piso permeável, o VR é de $0,0945 \mathrm{~m}^{3}\left(\mathrm{VR} / \mathrm{m}^{2}\right)$ (MOURA, 2013).

\section{Resultados}

A Tabela 4 apresenta os resultados da capacidade de retenção das técnicas de manejo de águas pluviais nas vias expressas, arteriais, coletoras e locais (Tabela 4).

Tabela 4 - Avaliação do desempenho das MPM aplicadas no sistema viário.

\begin{tabular}{|c|c|c|c|c|}
\hline Tipo de Via & Área da MPM $\left(\mathrm{m}^{2}\right)$ & $V R / m^{2}\left(m^{3}\right)$ & $\begin{array}{c}\text { Volume de retenção } \\
\left(\mathrm{m}^{3}\right)\end{array}$ & Capacidade \% \\
\hline \multicolumn{5}{|c|}{ Biovaletas } \\
\hline Expressa & 1500 & 0,487 & 730,5 & $186 \%$ \\
\hline Arterial & 500 & 0,487 & 243,5 & $109 \%$ \\
\hline Coletora & * & 0,487 & - & - \\
\hline Local & * & 0,487 & - & - \\
\hline \multicolumn{5}{|c|}{ Jardins de chuva } \\
\hline Expressa & 280 & 0,487 & 136,36 & $34 \%$ \\
\hline Arterial & 280 & 0,487 & 136,36 & $61,5 \%$ \\
\hline Coletora & 280 & 0,487 & 136,36 & $87,1 \%$ \\
\hline Local & * & 0,487 & - & - \\
\hline
\end{tabular}




\begin{tabular}{|c|c|c|c|c|}
\hline \multicolumn{5}{|c|}{ Canteiros pluviais } \\
\hline Expressa & 120 & 0,487 & 58,44 & $14 \%$ \\
\hline Arterial & 120 & 0,487 & 58,44 & $26 \%$ \\
\hline Coletora & 120 & 0,487 & 58,44 & $37 \%$ \\
\hline Local & 120 & 0,487 & 58,44 & $64 \%$ \\
\hline \multicolumn{5}{|c|}{ Sarjetas verdes } \\
\hline Expressa & ** & 0,487 & - & - \\
\hline Arterial & ** & 0,487 & - & - \\
\hline Coletora & 160 & 0,487 & 77,92 & $49,7 \%$ \\
\hline Local & 80 & 0,487 & 38,96 & $42,7 \%$ \\
\hline \multicolumn{5}{|c|}{ Piso Permeável } \\
\hline Expressa & 1000 & 0,0945 & 94,50 & $24,1 \%$ \\
\hline Arterial & 800 & 0,0945 & 75,60 & $34,1 \%$ \\
\hline Coletora & 650 & 0,0945 & 61,42 & $39,2 \%$ \\
\hline Local & 500 & 0,0945 & 47,25 & $51,7 \%$ \\
\hline \multicolumn{5}{|c|}{ Canteiros arborizados } \\
\hline
\end{tabular}

Observação: A arborização é considerada nessa pesquisa como uma MPM versátil que pode ser integrada a todos os tipos de via. A sua capacidade de retenção depende de características botânicas que não serão discutidas nessa análise.

Notas: * As biovaletas propostas nesta análise possuem $3 \mathrm{~m}$ de largura mínima, por isso não há espaço para sua aplicação nas vias coletoras e locais; ** Sarjetas verdes são aplicadas para promoverem o traffic calm (BONZI, 2015), por isso não são aplicadas em vias arteriais e expressas, caracterizadas pelo fluxo intenso de veículos.

Os resultados dessa avaliação demonstram que as performances das Melhores Práticas de Manejo variam de acordo com a hierarquia das vias. Quatro das cinco técnicas apresentam melhor desempenho em corredores menores, ruas coletoras e locais (Gráfico 1). 


\section{Gráfico 1 - Desempenho das MPM no sistema Viário.}

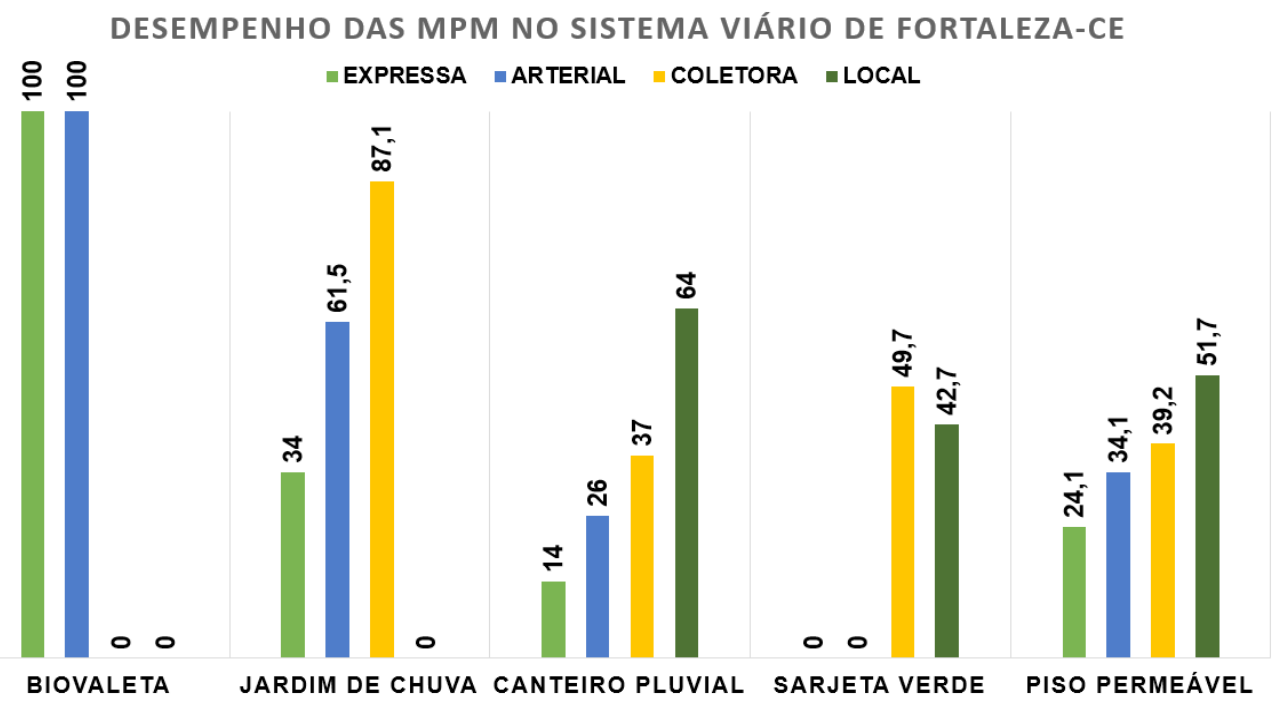

\section{Avaliação dos Dados}

Para classificar as melhores combinações entre MPM e via na retenção de águas pluviais, foram sugeridos três níveis de avaliação: Regular, Regular-Satisfatório e Satisfatório-Ideal (Tabela 5).

- Regular: nessa situação o desempenho da MPM é abaixo de $35 \%$, e por isso deve ser avaliada a possibilidade de uma combinação mais eficiente se for possível.
- Regular-Satisfatório: combinações em que a retenção pode chegar a $70 \%$ do volume, consideradas mais favoráveis.

- Satisfatório-Ideal: cenário em que a MPM pode ultrapassar $100 \%$ de retenção do volume precipitado, funcionando como um backup para eventos atípicos, ou seja, durante uma tempestade intensa ou num momento de falha do sistema de drenagem convencional. 
Tabela 5 - Classificação do desempenho das MPM APLICADAS NO SISTEMA VIÁRIO.

\begin{tabular}{c|c}
\hline $\begin{array}{c}\text { Classificação do desempenho das MPM } \\
\text { aplicadas no sistema viário }\end{array}$ \\
\hline Regular & $0-35 \%$ \\
\hline Regular-Satisfatório & $35,1-70 \%$ \\
\hline Satisfatório-Ideal & Acima de $70 \%$ \\
\hline
\end{tabular}

Vale ressaltar que qualquer uma das situações é favorável, o desempenho regular não significa que a aplicação das MPM deve ser descartada, visto que a sua presença, mesmo pequena, proporciona importantes serviços ambientais. O canteiro pluvial, por exemplo, pode ser aplicado em qualquer corredor, porém seu espaço limitado atrapalha a performance em avenidas expressas que apresentam maior dimensão. Assim, justificase sua aplicabilidade em ruas locais e mais estreitas, onde seu desempenho é mais eficiente na retenção do volume precipitado.

A classificação sugerida na Tabela 5 vem respaldar a definição das combinações mais eficientes entre as MPM e as tipologias de vias, ou seja, em quais tipos de corredores as técnicas de manejo têm maior capacidade de retenção. Portanto, aquelas que tiveram desempenho classificado como regular não foram recomendadas (Tabela 6), com exceção do piso permeável para via arterial que ficou muito próximo de $35 \%$.
Tabela 6 - Combinação entre as MPM e os tipos DE VIAS DISCRIMINADOS PELA LUOS.

\begin{tabular}{c|c|c|c|c}
\hline \multirow{2}{*}{ MPM } & \multicolumn{4}{|c}{ Tipos de vias } \\
\cline { 2 - 5 } & Expressa & Arterial & Coletora & Local \\
\hline Biovaleta & & & $\mathrm{X}$ & $\mathrm{X}$ \\
\hline Jardim de chuva & $\mathrm{X}$ & & & $\mathrm{X}$ \\
\hline Canteiro pluvial & $\mathrm{X}$ & $\mathrm{X}$ & & \\
\hline Sarjeta verde & $\mathrm{X}$ & $\mathrm{X}$ & & \\
\hline $\begin{array}{c}\text { Pavimento } \\
\text { permeável }\end{array}$ & $\mathrm{X}$ & & & \\
\hline $\begin{array}{c}\text { Canteiro } \\
\text { arborizado }\end{array}$ & & & & \\
\hline
\end{tabular}

Notas: Recomendável; X Não recomendável 


\section{Conclusão}

A partir da classificação apresentada na Tabela 6 é possível concluir que:

- Os canteiros pluviais e sarjetas são indicados para vias de menor porte, visto que se adequam aos espaços de calçadas e ruas mais estreitas, desempenhando um papel satisfatório na retenção do runoff e contribuindo para o controle de tráfego em vias locais residenciais.

- Os jardins de chuva podem ser aplicados em vias coletoras e arteriais e devem compor projetos paisagísticos de corredores comerciais e de serviços, englobando uma área de influência maior e exercendo um papel importante no controle de pontos de alagamentos que atrapalham a mobilidade nessas avenidas.

- As biovaletas devem contribuir para a captação e transporte do escoamento superficial em vias expressas caracterizadas por calçadas e canteiro central amplos, os quais comportam esse tipo de MPM. Sua aplicação pode promover o aumento de áreas verdes, criando um corredor permeável que integra diferentes bairros da cidade.

- Os pisos permeáveis constituem um complemento importante para ampliar o potencial de retenção do runoff principalmente nas áreas mais adensadas, onde é necessário utilizar todos os meios para aumentar a taxa de permeabilidade.

- Os canteiros arborizados representam a solução mais flexível onde não há possibilidade de propor as outras técnicas de manejo de águas pluviais; as árvores têm um papel fundamental no conforto ambiental dos corredores através da composição de passeios sombreados e agradáveis ao caminhar das pessoas.
A aplicação das MPM no sistema viário possibilita a consolidação de corredores verdes em múltiplas escalas, desde as ruas locais de um pequeno conjunto habitacional até a extensa avenida que atravessa a cidade. Por meio desses corredores, importantes áreas verdes da cidade podem ser conectadas, consolidando uma infraestrutura verde. A conectividade entre parques, praças e lagoas promovida por corredores de mobilidade adaptados às MPM é essencial para a constituição de uma cidade resiliente e a efetivação dos serviços ecológicos.

A fim de concretizar essa proposta, é essencial um aprofundamento sob a forma de projetos específicos consonantes com as características físicas e socioeconômicas dos corredores de mobilidade. Idealmente, essas orientações poderiam ser incorporadas à legislação e planos urbanísticos, que admitem os corredores de mobilidade como peças importantes no desenvolvimento urbano da cidade.

As transformações inerentes às técnicas de manejo vão além da retenção da água e possibilitam a valorização paisagística com a criação de áreas verdes em ruas e avenidas, formando corredores de integração entre praças e parques. A possibilidade de implantar jardins nas ruas incrementaria as políticas públicas de valorização dos espaços vegetados e arborizados e o programa de adoção de praças poderia ser ampliado para adoção de ruas, ou simplesmente, de um jardim.

Por fim, a infraestrutura verde é capaz de prevenir, por meio de suas propriedades regulatórias, os impactos negativos aos recursos naturais causados pelo crescimento urbano, que se tornou dependente de uma infraestrutura cinza limitada e rígida. A IEV em Fortaleza, consolidada com os corredores verdes, efetivaria a qualidade ambiental e urbanística, com a melhoria da drenagem e a criação de microclimas, favorecendo a resiliência da cidade e oferecendo melhor qualidade de vida. 


\section{Referências Bibliográficas}

ARAÚJO, Gustavo Henrique de Souza; ALMEIDA, Josimar Ribeiro de; GUERRA, Antônio José Teixeira. Gestão ambiental de áreas degradadas. 11. ed. Rio de Janeiro: Bertrand Brasil, 2014. 322p.

BENEDICT, Mark A.; MCMAHON, Edward T. Green Infrastructure: linking landscapes and communities. Washington, DC: Island Press, 2006.

BONZI, Ramón Stock. Andar sobre Água Preta: a aplicação da Infraestrutura Verde em áreas densamente urbanizadas. 2015. Dissertação (Mestrado em Arquitetura e Urbanismo) - Universidade de São Paulo, São Paulo, 2015. Disponível em: https://bit.ly/2IOu9Qk. Acesso em: 20 nov. 2017.

BONZI, Ramón Stock. Paisagem como infraestrutura. In: VARGAS, Heliana Comin: PELLEGRINO, Paulo; MOURA, Newton Becker (org.). Estratégias para uma infraestrutura verde. Barueri, SP: Manole, 2017. p. 1-24.

CHELLERI, Lorenzo et al. Resilience trade-offs: addressing multiple scales and temporal aspects of urban resilience. Environment and Urbanization, Thousand Oaks, v. 27, n. 1, p. 181-198, 2015. DOI: 10.1177/0956247814550780.

COM chuva, carros boiam na Avenida Aguanambi, em Fortaleza. G1 Ceará, Fortaleza, 8 jan. 2017. Disponível em: https://glo.bo/2KEfvgQ. Acesso em: 20 mar. 2017.

CORMIER, Nathaniel S.; PELLEGRINO, Paulo Renato Mesquita. Infra-estrutura verde: uma estratégia paisagística para a áqua urbana. Paisagem e Ambiente, São Paulo, n. 25, p. 127 142, 2008. Disponível em: https://bit.ly/31VN1Vi. Acesso em: 14 nov. 2017.

FABOS, Julius Gy. Introduction and overview: the greenway movement, uses and potentials of greenways. Landscape and Urban Planning, Amsterdam, v. 33, n. 1/3, p. 1-13, 1995. DOI: 10.1016/0169-2046(95)02035-R

FORTALEZA 2040. Fortaleza: Iplanfor, v. 5, n. 2, 2015. Disponível em: https://bit.ly/2INeReF. Acesso em: 29 set. 2017

FORTALEZA. Lei complementar $n^{\circ} 236$, de 11 de agosto de 2017a. Dispõe sobre o parcelamento, o uso e a ocupação do solo no Município de Fortaleza, e adota outras providências. Diário Oficial do Município Fortaleza, Fortaleza, 11 ago. 2017. Suplemento.

FORTALEZA. Prefeitura de Fortaleza divulga andamento das obras na Avenida Aguanambi. Fortaleza: Prefeitura Municipal, 2017. Disponível em: https://bit.ly/2ttMc8y. Acesso em: 22 out. 2017b.

GEHRELS, Hans et al. Designing green and blue infrastructure to support healthy urban living. [S. I.]: TO2 Federatie, 2016. Disponível em: https://bit.ly/2xoF39j. Acesso em: 18 nov. 2017

HUBER, Jeffrey et al. Low Impact Development: a design manual for urban areas. Fayetteville: University of Arkansas, 2010

LIMA, Gerson Amaral. Campus da Fiocruz no Ceará: aplicação das infraestruturas verdes no contexto do semiárido. 2016. Dissertação (Mestrado em Paisagem e Ambiente) - Faculdade de Arquitetura e Urbanismo, Universidade de São Paulo, São Paulo 2016. 151 p.:il. Disponível em: https://bit.ly/2NtWuQH. Acesso em: 10 set. 2017.

LITTLE, Charles E. Greenways for America. Baltimore: The John Hopkins University Press, 1990. $237 \mathrm{p}$.
MOURA, Newton Cello Becker de. Biorretenção: tecnologia ambiental urbana para manejo das águas de chuva. Tese (Doutorado em Paisagem e Ambiente) Faculdade de Arquitetura e Urbanismo, Universidade de São Paulo, São Tde-30052014-104153.

NETO, Lira; ALBUQUERQUE, Claudia. História urbana e imobiliária de Fortaleza: biografia sintética de uma cidade. São Paulo: Barba, 2014.

PINHEIRO, Maitê Bueno. Plantas para infraestrutura verde e o papel da vegetação no tratamento das águas urbanas de São Paulo: identificação de critérios para seleção de espécies. 2017. Dissertação (Mestrado em Paisagem e Ambiente) - Faculdade de Arquitetura enco 27062017-141958.

PORTLAND (OR). Stormwater management manual. Portland: Environmental Services, 2016. Disponível em: https://bit.ly/2ZPeTbE. Acesso em: 25 out. 2017.

PORTLAND (OR). Stormwater solutions handbook: when it gets to the ground. Portland: Environmental Services, 201-. Disponível em: https://bit.ly/2Ja9QMa. Acesso em: 24 nov. 2017.

PRINCE GEORGE (MD). Low-impact development design manual. Prince George: Department of Environmental Resources, 1999. Disponível em: https://bit.ly/2XbiNia. Acesso em: 28 nov. 2017.

SEMCOG. Low impact development manual for Michigan: a design guide for implementors and reviewers. Detroit: Southeast Michigan Council of Governments, 2008. Disponível em: <https://bit.ly/2NayjpX> Acesso em: 23 nov. 2017.

SILVA, Francisco Osny E. da; PALÁCIO JÚNIOR, Francisco Flávio Rocha; CAMPOS, José Nilson Bezerra. Equação de chuvas para Fortaleza-CE com dados do pluviógrafo da UFC. Revista DAE, São Paulo, n. 192, p. 48-59, 2013. DOI: 10.4322/dae.2014.106.

UNITED STATES. Department of Defense. The low impact development manual, UFC-3-21010. Washington, DC: Department of Defense, 2004. Disponivel em: https://bit.ly/2NdkyHf Acesso em: 28 nov. 2017.

Yu, Kongjian; Li, Dihua; Li, Nuyu. The evolution of greenways in China. Landscape and Urban Planning, Amsterdam, v. 76, n. 1-4, p. 223-239, 2006. DOI: 10.1016/j.landurbplan.2004.09.034. 
Raquel Moraes Vitor Cortez

Universidade de Fortaleza (Unifor). Curso de Arquitetura e Urbanismo.

Av. Washington Soares, 1321, Fortaleza, CE, Brasil, CEP 60811-905.

CV: http://lattes.cnpq.br/0861164304837786

Orcid: https://orcid.org/0000-0001-7379-2529

E-mail: raquelmvitor@unifor.br

Newton Celio Becker de Moura

Universidade Federal do Ceará (UFC). Departamento de Arquitetura e

Urbanismo.

Av. da Universidade, 2890, Benfica, Fortaleza, CE, Brasil, CEP 60020-181.

CV: http://lattes.cnpq.br/0716808700305586

Orcid: https://orcid.org/0000-0003-0541-2680

E-mail: arqnewton@yahoo.com

Clara de Oliveira Jucá Machado

Universidade de Fortaleza (Unifor). Curso de Arquitetura e Urbanismo.

Av. Washington Soares, 1321, Fortaleza, CE, Brasil, CEP 60811-905.

CV: http://lattes.cnpq.br/4376817126470901

Orcid: https://orcid.org/0000-0001-9749-5393

E-mail: clarajmachado@edu.unifor.br

Nota do Editor

Submetido em: 31/05/2018

Aprovado em: 14/03/2019

Revisão do texto: Tikinet 